\title{
Approaches to the evaluation of the effectiveness of innovative development of the machine-building enterprise strategy
}

\author{
T. Gerashchenkova ${ }^{1, *}$ \\ ${ }^{1}$ Bryansk State Technical University, Bryansk, Russian Federation
}

\begin{abstract}
For the effectiveness assessment in the strategy of enterprise development it is expedient to carry out the regular monitoring of activities. For that there are must be estimated moment indices, rates of indices increase. A standard sequence is under formation characterizing rates of growth of some indices regarding others. Quantitative indices in sequences formed are established reasoning from the necessity to ensure the innovation development of an enterprise. In this case the degree of a correspondence of actual indices structure preliminarily formed by a standard one witnesses testifies management effectiveness which is quantitatively characterized by rank correlation narrowness. Specifying the priority sequence of indices one can design and establish in programs and plans of enterprise strategic development a model of successful economic activities.
\end{abstract}

\section{Introduction}

The purpose of the assessment of the effectiveness of innovative development of the machine-building enterprise strategy is to identify how the characteristics of the chosen model of economic entity in the long term, meet the requirements of efficiency and competitiveness. In this regard, is it necessary to study management and business activities in order to establish a rational choice of approach to achieving the goals, the efficiency of the reaction to changes in the external environment and onfarm situation, revealing the evidence of the enterprise increasing stability, entailing the improvement of organization level of the economic entity as a system.

In order to monitor the effectiveness of the company development in the implementation of innovative development strategies it is advisable to study a set of composite indexes that have a hierarchical structure, using the concept of economic growth proportionality, and indexes characterized by a certain normative structure, adapted and refined in accordance with the essence of the phenomenon under investigation.

\section{Rationale}

An effective development strategy must ensure a positive trend of promising production and economic parameters of an economic entity, be based on efficient production processes, sustainable competitiveness of the enterprise. In connection with this the analysis of the achievement of targets (settings) and performing mandated activities [1-8] seem to be unreasonable. These approaches are inherently static. Under the strategic approach, involving lengthiness of the process in time, it is important to monitor the processes occurring in their dynamics. Thus, in this case it is necessary to monitor $[9,10]$, study growth rates and growth rates of some indexes relative to other.

\section{Theoretical part}

To assess the effectiveness and management quality of production and economic activity, I.M. Syroezhin [11] proposed to use the method of the investigation of "economic growth structure", which was later developed in the research [12-15] for the definition of "economic growth proportionality",

The study of economic growth proportionality seems to be useful for innovative development strategy effectiveness. However, objects and features of the content of this concept required to adapt the aims presented above.

In fact, the forming index structure, being the subject of evaluation may take the form of any combination of indexes contained in the regulatory framework and reflecting the existing realities and priorities of the management system in the implementation of development strategies. The presence of deviations in the structure shows a decline in the level of quality strategy during the study period. The magnitude of the deviations can be judged on the content and nature of the activities in the area of concern, as well as the mistakes made in the design and implementation of development strategies.

The number of indexes in generated sequences is set on the basis of the purpose of assessment activities, the availability of information and the accuracy of the desired results. In order to assess the company development strategy as a whole a group of system-wide indexes should be considered. The assessment of the innovative development strategy involves the use of a specific detailed structure of indexes. 
Due to the importance of products manufactured at the machine-building enterprises, which characterizes the level of technological development of the society, the priority in the structure of regulatory indexes is given to the satisfaction of the needs of consumers of products, their desire to purchase products of a given enterprise. The condition for achieving this development parameter is the growth of production, or a cheaper way of production or the execution of the first and second conditions simultaneously. In case of customer satisfaction with innovative products or use of innovative technologies for the production, an appropriate investment is required, so investments will be the last in this chain of indexes.

Thus, the regulatory framework of the indexes should include the following groups of indexes: the objective function - the importance of innovative development results for the consumer, as well as the results of using the potential of the enterprise and the amount of on-going expenses.

We assume the following general conditions under which economic interests of the innovator, the investor and the consumer coincide: the increase in a customer value of the goods must be greater than the increase in the efficiency of the innovator in the processes of the strategy implementation, which, in turn, must be higher than the efficiency gains of investing in the implementation of the activities of the given strategic alternative, ie,

$$
\Delta\left\{P^{k c}\right\}>\Delta\left\{E^{i n n}\right\}>\Delta\left\{E^{i v n}\right\},
$$

where: $\Delta\left\{P^{k c}\right\}$ - increase of customer value of the product; $\Delta\left\{E^{i n n}\right\}$ - increase the efficiency of the innovator in the implementation of innovation and investment strategy; $\Delta\left\{E^{i v n}\right\}$ - investment efficiency gains in the implementation of the activities of the strategic alternatives.

It is proposed to introduce the indexes, calculated with the help of the index method, into the above mentioned groups, since this approach, reflecting a change in the dynamics of indicators, allows to achieve a single dimension. [16]

It is also necessary to take into account the factor of time money value using a discount rate, on the basis of the source data in terms of value.

Lets consider the figures included in the formula 1 group.

The usefulness of the goods $\left(P^{k c}\right)$ - is an assessment of the degree of satisfaction as a result of its use. Usefulness is determined by the characteristics of goods, as well as economic factors (price, transaction costs during its use, etc.). It can be defined as an increment value of production of the enterprises on the basis of the calculation of the product competitiveness index. [17]

This method is based on a comparison of quality and price indexes. Buyers taking the decision to purchase, either prefer quality, losing in the price, or being satisfied with the lower price, are dissatisfied with the quality of purchase. Thus, it seems advisable to get Competitiveness Index $\left(I_{k c}\right)$ by multiplying the price index $\left(I_{c}\right)$ and quality $\left(I_{k}{ }^{i}\right)$.

1. It is necessary to calculate the individual indexes of competitiveness in quality, characterizing the deviation of meaningful quality indicators (by $I_{k}{ }^{i}$ ) of the products being analyzerd from the basic product indicatorsn $[18,19]$. The base products are the products manufactured prior to the implementation of innovative investment strategy.

$$
\begin{gathered}
I_{k}^{i}=\frac{k^{i}}{k^{b}}, \\
I_{k}^{i}=\frac{k^{b}}{k^{i}},
\end{gathered}
$$

where: $I_{k}{ }^{i}-$ Index of appropriate quality indicator; $k_{b}, k_{i}-$ Basic and investigational value of quality indicators..

Formula 2 should be used if an increase in the dynamics of index values indicates the quality of growth. Formula 3 is intended for cases where an increase in the test speaks about a decrease in the quality of products in general. The definition of quality indexes of both the test, and the sample must be carried out using the same methods. [19]

2. Single parametric indexes $\left(I_{k}{ }^{i}\right)$ are combined in a group index $-\Sigma I_{k}$. The calculation of the index requires the determination of the weight coefficient of the examined characteristics of evaluated products, the sum constituting a unit. For food products with a large variety of approaches to the subjective assessment of the significance of various quality parameters, it is impossible to give preference to any of them, because if any of the indexes do not comply with the quality level, products become unfit for consumption, regardless of the subjective evaluation. In this regard, the weight coefficients can be represented as an equal share for all tested parameters

$$
\sum I_{k}=\sum_{i=1}^{n} \frac{\frac{1}{i} \times I_{k}^{i}}{i},
$$

3. The index of competitiveness for the price is calculated:

$$
I_{c}=\frac{c \times \frac{1}{(1+r)^{t}}}{c^{b} \times \frac{1}{(1+r)^{t-1}}}
$$

where: $c$-retail price of the product being analyzed; $c^{b}-$ retail price of the basic product .

Since agribusiness is a manufacturer of products not subject to or slightly exposed to obsolescence, the price of the base product can be considered the price of similar products in the previous year, especially since the introduction of new technology or the use of breeding material that is the most common type of innovation in the agricultural sector and the manufacture of food products, all manufactured products in the next period of time will characterize the impact of innovation and investment process.

It should noted that the prerequisite is the similarity of pricing methodology for previously manufactured and a new (or produced by a new technology or using new materials) products.

Total competitiveness index is calculated as the sum of two previously calculated indices:

$$
I_{k c}=I_{k}+I_{c}
$$


This is followed by the identification of indexes that most adequately reflect the efficiency of innovation and investment activity, taking into account the heterogeneity of performance criteria, from the standpoint of innovators and investors.

From the standpoint of innovation active enterprises the following conditions must be identified:

1) cost growth in the sales of innovative products in total sales $\left(I_{Q}\right)$

$$
I_{Q}=\frac{Q \times \frac{1}{(1+r)^{t}}}{Q^{b} \times \frac{1}{(1+r)^{t-1}}}
$$

where: $Q$ - sales of innovative products and services (and products produced by innovative technologies) in the subsequent period; $Q^{b}$ - the same indicator of the previous period

2) the reduction of resource consumption when using a new technology, in comparison with the previous one $\left(I_{R}\right)$

$$
I_{R}=\frac{R^{b} \times \frac{1}{(1+r)^{t-1}}}{R \times \frac{1}{(1+r)^{t}}},
$$

where: $R$ - resource consumption when using a new technology, or in each subsequent year; $R^{b}-$ resource consumption before the implementation of the new technology, or in each previous year.

3) growth of enterprise value, estimated by the value of assets before and after the launch of the innovativeinvestment strategy (may be due to both the growth of value of fixed assets and intangible assets) $\left(I_{A}\right)$

$$
I_{A}=\frac{A \times \frac{1}{(1+r)^{t}}}{A^{b} \times \frac{1}{(1+r)^{t-1}}},
$$

where: $A$ - value of the assets after the launch of the innovative-investment strategy, or in each subsequent year; $A^{b}$ - value of the assets prior to the implementation of innovative investment strategy, or in each previous year

4) increase in wholesale prices for products compared to previously manufactured analogue $\left(I_{c}^{i n n}\right)$

$$
I_{c}^{\text {inn }}=\frac{c^{i n n} \times \frac{1}{(1+\kappa)^{t}}}{c^{b} \times \frac{1}{(1+r)^{t-1}}}
$$

where: $c^{i n n}$ - the wholesale price of an innovative product, or a product produced by the innovative technology; $c^{b}-$ the wholesale price of previously manufactured analog of new products, or the price in the previous period.
From the point of view of the investors effectiveness confirmation also requires compliance with several conditions:

1) growth of investment in innovation $\left(I_{V}^{i n \eta}\right)$

$$
I_{V}^{i n v}=\frac{V^{i n v} \times \frac{1}{(1+r)^{t}}}{V^{i n v b} \times \frac{1}{(1+r)^{t-1}}},
$$

where: $v^{i n v}$ - the volume of investments in the new portfolio, and in the subsequent period of time; $v^{i n v b}-$ the volume of investmnents of the previous period.

2) revenue growth of investment in innovation in the total amount of income from investments $\left(I_{n p}{ }^{i n v}\right)$

$$
I_{n p}^{i n v}=\frac{n p^{i n v} \times \frac{1}{(1+r)^{t}}}{n p^{i n v b} \times \frac{1}{(1+r)^{t-1}}},
$$

where: $n p^{i n v}$ - profits under the new investment portfolio; $n p^{i n v b}$ - the amount of profit of the previous period.

The greatest difficulty in the next step is intra-ranking figures because of the diversity of implemented corporate and functional strategies with their corresponding plurality of combinations of priority indicators. In this regard, the logic of construction of a ranked number of indexes should be based on preferences for specific conditions under study. [20]

Based on the practice of the factor analysis of the efficiency in the analysis of interdependence of the categories' costs - Revenue - Profit " [21, 22], we can specify the indexes, using the above mentioned inequality (Formula 1).

$$
I_{k c}>I_{Q}>I_{r}>I_{A}>I_{c}^{i n n}>I_{V}^{i n v}>I_{n p}^{i n v}
$$

So we formed a normative set of indexes agreed with the previously established priorities. It reflects the presence of innovation and investment component in the process of achieving strategic goals. In the framework of the adopted in the analysis of the regulatory framework, criterial values of selected indexes can vary within certain limits, which helps to preserve the consistency of the normative set.

By setting a priority sequence of indexes, its possible to design a model of a successful economic activity, and secure it in the programs and plans.

Management efficiency is proved by the degree of conformity of the actual structure of the indexes with preliminary generated normative structure, which is quantified by the tightness of rank correlation. For its definition Spearman rank correlation coefficient is used in mathematical statistics. The works of I.M. Syroezhin provide the evidence and justification of the possibility of using this characteristic to assess a variety of options of disorder ranks indexes in structures [11]. 


\section{Experiment results}

Testing at a number of engineering enterprises have confirmed the usefulness of the proposed approach to the determination of the effectiveness of innovative development strategy. The study covered the period from 2005 , which made it possible to evaluate the aftereffects of innovative activities used from 2011.

On the basis of the established priorities of the rate of growth indexes we calculated rank correlation coefficients. According to the coefficients the graphs rreflect the dynamics of the change of the Spearman rank activity coefficient (Fig. 1).

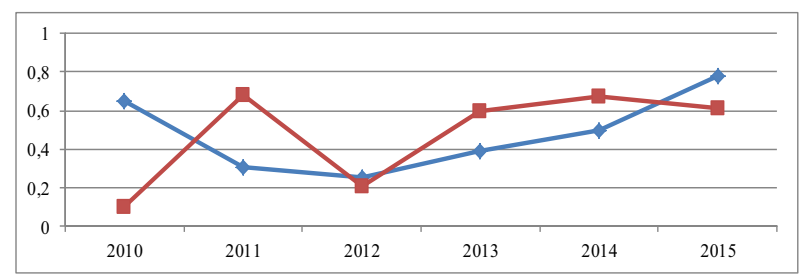

— CJSC Bryansk automobile plant

JSC Bryansk repair and engineering works

Fig. 1. Spearmen rank coefficient dynamics.

Significant undulation of correlation coefficient, presented in the figure, indicate instability of the enterprise development in the process of the strategy implementation, while the graph having a flat curve, proves the success of the development.

Identification of trends in terms of the effectiveness of the implementation of innovative development strategies sums up the efforts of the company management and serves as a basis for the further conduct of detailed evaluations of the policy carried out by it, a system of interaction with business partners, competitors, financial institutions, infrastructure and complex as well as with the authorities.

It should be noted that this approach is particularly relevant to machine-building enterprises in the conditions of instability of the environment and limited financial resources, as the assessment of the effectiveness of investments in innovation traditional approaches often demonstrates the futility of investing due to a prolonged payback period. Demonstrating positive dynamics of the proposed indexes, corresponding to the predetermined priorities, it is possible to evaluate from a new perspective both efficiency and appropriateness of innovative activities.

\section{Conclusion}

The analysis and evaluation of innovative development strategies should be carried out with the help of a number of regulatory indexes, comparing the growth rates and simple indexes with those under traditionally implemented scenarios of the economic system development. The effectiveness of this approach is confirmed by the approbation conducted at innovation-oriented machinebuilding enterprises. Conducted expert surveys confirmed the validity and acceptability of the above approach and widened the understanding of its potential use.

\section{References}

1. Y. Brigham, L. Gapensk, Financial Management: Transl. from English (1997)

2. I.V. Bryantseva, The economic stability of the enterprise: essence, evaluation, management (Publishing house KHGTU, Khabarovsk, 2003)

3. L.T. Gilyarovskaya, D.V. Lysenko, D. Endovitsky, Comprehensive economic analysis of economic activity (Prospect, Moscow, 2008)

4. V.N. Lazhentsev, Proceedings of Komi Scientific Center of the Ural Branch of the Russian Academy of Sciences (RAS), 13, 107-113 (2013)

5. T.B. Leybert, Economics, 9(46), (2008)

6. A.I. Solyanik, Control systems and information technology: Scientific and Technical Journal, 1.3(31), 410-413 (2008)

7. A.I. Solyanik, O.J. Kravets, Control systems and information technology: Scientific and Technical Journal, 2.1(32), 204-207 (2008)

8. N.N. Bondarenko, N.S. Buzygina, L.I. Wasilewska, Statistics: indexes and methods of analysis (Modern School, 2005)

9. D.S. Buklagin, Development of information security and innovation: Publications, 143, 3-12 (2002)

10. B.Y. Serbinovsky, E.V. Rudick, Monitoring of labour productivity (South. Federal Univ, Novocherkassk, Lick, 2010)

11. I.M. Syroezhin, The planned. planning. Plan (theoretical essays) (Economics, Moscow, 1986)

12. V.A. Vinokourov, G.L. Azoev, Managing the development of industrial association (MIM, Moscow, 1989)

13. V.V. Vikharev, Herald of SRSTU (NPI), 3, 132-135 (2012)

14. V. Novikov, The Economist, 8, 46-52 (1992)

15. J.S. Merkumov, The organization and financing of investments (INFRA-M, Moscow, 2002)

16. T.M. Geraschenkova, Scientific notes of Petrozavodsk State University, 1(138), 94-99 (2014)

17. E.V. Tyapushova, Herald of BFU name of I.Kant, 3, 119-124 (2012)

18. G.L. Bagiev, V.M. Tarasevich, J. Ann, Marketing (Economics, Moscow, 2001)

19. N.P. Vashchekin, Marketing (Publishing House FBKPRESS, Moscow, 2004)

20. T. Kaneko, Problems of the theory and practice of management, 3, 80 (2002)

21. M.A. Ryazanov, Issues of innovative economics, 9(9), 3-12 (2011)

22. A.G. Savitskaya, Analysis of economic activity of the enterprise (INFRA-M, Moscow, 2009) 